\title{
Enhancement of microwave ring resonator based on poly-lactic acid thermoplastic substrate
}

\author{
Nurul Hanani Manab, Elfarizanis Baharudin, Fauziahanim Che Seman, Rosnah Mohd Zin \\ Faculty of Electrical and Electronic Engineering, Universiti Tun Hussien Onn Malaysia, Malaysia
}

\begin{tabular}{|c|c|}
\hline Article Info & ABSTRACT \\
\hline Article history: & In this paper, the development of a single-port microwave ring resonator \\
\hline Received Nov 22, 2019 & (MRR) sensor based on a thermoplastic material, which is poly-lactic acid \\
\hline Revised Jun 20, 2020 & identify the dielectric properties of PLA in terms of dielectric constant $(2.25)$ \\
\hline Accepted Jul 15, 2020 & $\begin{array}{l}\text { and loss tangent }(0.0001) \text {. The PLA substrate was fabricated using a hot } \\
\text { press machine and with the same thickness }(1.6 \mathrm{~mm}) \text { as FR4. Hence, to }\end{array}$ \\
\hline Keywords: & $\begin{array}{l}\text { consider the PLA as microwave substrate, microwave ring resonator (MRR) } \\
\text { operating at } 1.1 \mathrm{GHz} \text { resonance frequency was designed, simulated, }\end{array}$ \\
\hline Microwave ring resonator & and measured. Based on the observation, the return loss of MRR for \\
\hline Poly-lactic acid & the simulation and the measurement of the conventional design are $-5.37 \mathrm{~dB}$ \\
\hline Q-factor & and $-5.02 \mathrm{~dB}$, respectively. The quality factor (Q-factor) for both are 122.22 \\
\hline Return loss & and 183.33 , respectively. Then, the enhanced coupling gap method was \\
\hline Thermoplastic & $\begin{array}{l}\text { applied to improve the performance of MRR sensitivity in terms of return } \\
\text { loss and Q-factor. It is observed that the return loss of the enhanced design }\end{array}$ \\
\hline & $\begin{array}{l}\text { for the simulation and the measurement are }-26.67 \mathrm{~dB} \text { and }-20.23 \mathrm{~dB} \text {, } \\
\text { respectively, and the Q-factor are } 122.22 \text { and } 200 \text {, respectively. Thus, } \\
\text { the performance of the MRR based on different designs were compared in } \\
\text { order to validate the sensor's sensitivity and PLA can be recognized as } \\
\text { a substrate material for RF and microwave applications. }\end{array}$ \\
\hline
\end{tabular}

This is an open access article under the CC BY-SA license.

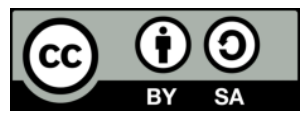

\section{Corresponding Author:}

Elfarizanis Baharudin,

Faculty of Electrical and Electronic Engineering,

Universiti Tun Hussein Onn Malaysia,

86400 Parit Raja, Batu Pahat, Johor, Malaysia.

Email: elfa@uthm.edu.my

\section{INTRODUCTION}

Microwave resonators are integral components in a microwave communication system and are used in a variety of applications including filters, oscillators, amplifiers and other applications that contain series and parallel RLC resonant circuits [1-3]. The two criteria that describe the resonator are (i) the resonant frequency, wherein the energy in the cavity attains maximum value and (ii) Q-factor, which is the capacity of the electromagnetic energy storage. The Q-factor at low frequency is between 50 to 500, and the resonator bandwidth is inversely proportional to the Q-factor. High Q-factor resonators have narrow bandwidths. A high Q-factor is obtained with the highly reactive RLC circuits $[4,5]$. Thus, the RLC circuit is integral to the microwave ring resonator (MRR) structure's design, which consists of the substrate, transmission line and patch [6-8].

Normally, the printed circuit board (PCB) is the common material that acts as the substrate in microwave devices. Thus, a newly developed substrate based on thermoplastic is proposed to replace the PCB substrate. Poly-lactic acid (PLA) has been selected in this research because it is a natural material 
and that it will help to conserve the environment after the disposal process by not harming the ecosystem [9, 10], as compared with commercial substrates such as the PCB. In addition, a PCB substrate is complicated to be recycled, is a high risk to the environment and requires high cost for its disposal process [11-13]. Therefore, to ensure that PLA is able to act as a commercial substrate, the MRR was designed using the CST software at the resonant frequency of $1.1 \mathrm{GHz}$.

In order to verify the dielectric properties of the newly developed substrate, the coaxial probe method was proposed to measure the dielectric properties of the material and to verify the properties in terms of dielectric constant and loss tangent in broadband frequency [14]. According to [15], the open-ended coaxial probe method is a non-resonant method which is able to determine the material's characterization and has high accuracy for high loss materials. In [10], PLA was applied as the substrate for an antenna. In this paper, the MRR was designed based on the PLA substrate. To improve the performance of the MRR, the coupling gap method was applied for all designs. The separation between the feed line and the ring, called the coupling gap, is shown in Figure 1.

According to $[16,17]$ an enhanced coupled MRR was introduced in their research. The larger distance between the feed line and the ring does not affect the resonant frequency. The coupling method could improve the performance of the resonator [7]. In the enhanced coupling method, two coupling gaps on each port are formed between the enhanced feed lines and the ring. The enhanced coupling is implemented by inserting the feed lines into the annular ring element. The technique improves the Q-factor by increasing the gap size. Nevertheless, the coupling method is suitable for all resonator designs to improve the performance of resonator applications [7].

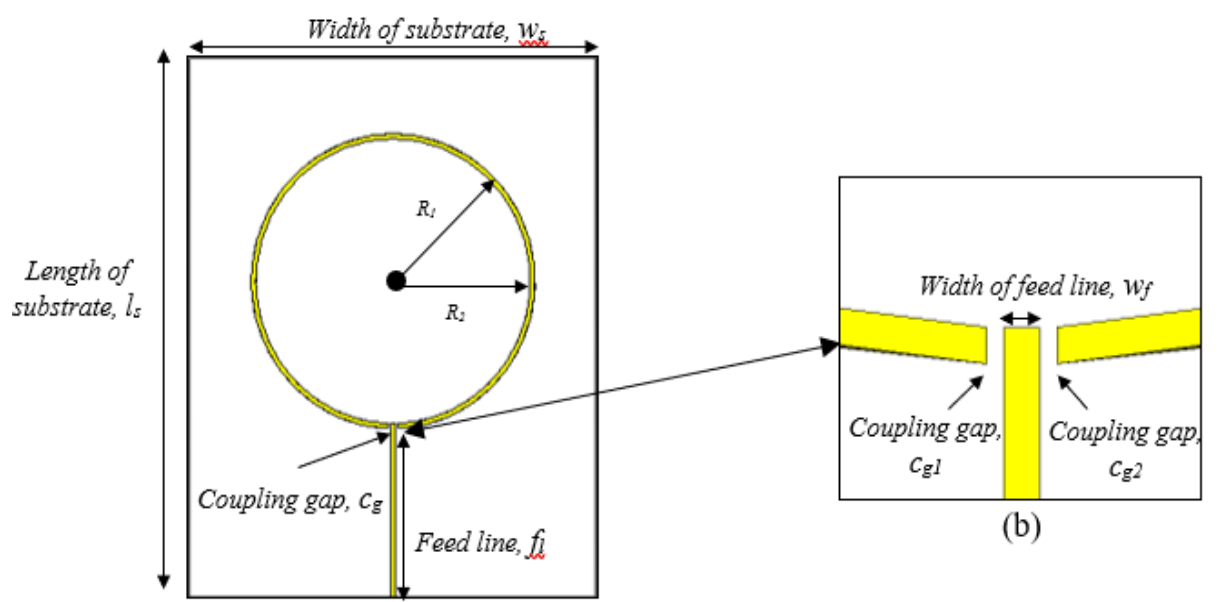

(a)

Figure 1. Proposed key-shaped MRR design

\section{RESEARCH METHOD}

\subsection{Part A: Formulation of MRR}

Based on Figure 1, the design of the ring resonator consists of a single port and a coupling gap between the feed line and the ring, which is sufficient for the resonance condition as in (1), where $R$ is the mean radius of the ring and $n$ is the harmonic order of resonance $[8,17,18]$.

$$
2 \pi R=n \frac{\lambda g}{2} \quad \text { for } \quad n=1,2,3 \ldots
$$

Next is finding the effective permittivity, $\varepsilon_{\text {eff }}$. The formula is expressed in (2), where $\varepsilon_{r}$ is the value of the dielectric constant of the substrate, $h$ is the height of the substrate and $d$ is the thickness of the substrate $[8,17,18]$.

$$
\varepsilon_{e f f}=\frac{\varepsilon_{r}+1}{2}+\frac{\varepsilon_{r}-1}{2} \frac{1}{\sqrt{1+12 \frac{d}{h}}}
$$


Thus, the guided wavelength $\lambda_{g}$ can be related to frequency by (3), where $c$ is the speed of light $3 \times 10^{8} \mathrm{~m} / \mathrm{s}, f$ is the resonant frequency and $\varepsilon_{\text {eff }}$ is the effective permittivity $[8,17,18]$.

$$
\lambda g=\frac{c}{f \sqrt{\varepsilon_{e f f}}}
$$

Commonly, the characteristic impedance $Z o$ is $50 \Omega$, and the dielectric constant of the substrate and the width of the resonator can be calculated as in $(4)[8,17,18]$.

$$
\begin{array}{ll}
W=\frac{\mathcal{E}_{r}+1}{2}+\frac{\mathcal{E}_{r}-1}{2}\left[\frac{1}{\sqrt{1+12 \frac{h}{w}}}+0.04\left(1-\frac{w}{h}\right)^{2}\right] & \text { for } \frac{w}{h} \leq 1 \\
W=\frac{\varepsilon_{r}+1}{2}+\frac{\varepsilon_{r}-1}{2}\left[\frac{1}{\sqrt{1+12 \frac{h}{w}}}\right] & \text { for } \frac{w}{h} \geq 1
\end{array}
$$

Then, the transmission line, which is called as the feed line, is calculated using (5), where $\lambda \mathrm{g}$ is the wavelength of the transmission line divided by a quarter-wavelength, i.e. by four [8, 19]. The feed line and the ring resonator are the printed transmission lines with the width chosen for the $50-\Omega$ characteristic impedance [17, 18]. There is a coupling gap between the feed lines and the ring, where the gap that is introduced as a capacitance gap will affect the performance of resonator in terms of return loss and Q-factor. The single-port design is proposed due to the simple configuration and that it can reduce the number of control parameters. Thus, a single-port resonator produces the dielectric constant only, as well as the single-mode response $\left(\mathrm{T}_{\mathrm{M}}\right.$ or $\mathrm{T}_{\mathrm{E}}$ mode) [20].

$$
\text { Feed line: } f_{l}=\frac{\lambda g}{4}
$$

The inner radius and outer radius of the ring are calculated using (6) and (7), where $R$ is the radius of the resonator and $W$ is the width of the resonator [8, 17-19].

$$
\begin{aligned}
& \text { Inner radius } R_{1}=R-\frac{w}{2} \\
& \text { Outer radius: } R_{2}=R+\frac{w}{2}
\end{aligned}
$$

The Q-factor value of a dielectric resonator is the ratio between the energy stored within the resonator, which is related to the capacity of the electromagnetic energy storage [4]. Normally, a high Q-factor is desired for resonator measurements [6]. Therefore, the proposed sensor device performs a high Q-factor with high sensitivity and accurate measurement for characterizing the properties of a material. The Q-factor can be determined by (8), where $\omega_{o}$ is the center of the resonant frequency and $\Delta \omega$ is bandwidth at $-3 \mathrm{~dB}[21,22]$.

$$
Q=\frac{2 \omega_{o}}{\Delta \omega}
$$

\subsection{Part B: Fabrication process of PLA}

Figure 2 presents the fabrication process of PLA. The fabrication process was started by measuring the volume of the mold $(240 \mathrm{~mm} \times 240 \mathrm{~mm} \times 16 \mathrm{~mm})$. Based on the volume of the mold, the mass of the PLA pellets was defined by density, which is the ratio of the mass over the volume of the material, in $\mathrm{g} / \mathrm{cm}^{3}$. Next was the preheating process of the material at $70^{\circ} \mathrm{C}$ for about 30 minutes using the domestic oven. The purpose of the preheating process is to stabilize the material's condition when the surrounding temperature changes. In addition, it can produce a clear and smooth surface of the developed substrate. After 30 minutes, the PLA pellets were flattened on the mold and covered by aluminum plates at the top 
and bottom of the mold. Then, the mold was placed into the hot press machine for the next process. The preheating process continued after the mold was inserted into the hot press machine. The preheating process will take up to 30 minutes at a temperature of $185^{\circ} \mathrm{C}$. The next process was the melting process at the appropriate temperature and pressure for 0.5 tonnes of the substrate. The temperature of the hot press machine for the upper and lower platen was set at $185^{\circ} \mathrm{C}$ and the duration was 18 minutes for the melting process. Next was the cooling process, where water was flowed onto the hydraulic system of the hot press machine for around 30 to 45 minutes until the temperature dropped off to $40^{\circ} \mathrm{C}$. The last process was removing the substrate from the mold.

\subsection{Part C: Identification of PLA dielectric properties}

The PLA properties were identified using the open-ended coaxial probe measurement method. This method was proposed to ensure that the properties of PLA were synchronized with the design of the resonator using the CST software. The open-ended coaxial probe method functioned to measure dielectric constant, loss factor and loss tangent of the material. Figure 3 presents the open-ended coaxial probe for the measurement of the dielectric properties, where the coaxial probe was connected to the vector network analyzers (VNA) and the PLA substrate was placed under the coaxial probe. Before the dielectric properties are measured, a calibration of the dielectric probe was required, which performed with three types of loads; short circuit, free space and load. The calibration's main function was to check the suitability of the calibration before placing the material on the base of the dielectric probe. The main advantage of the open-ended coaxial probe technique is that it is a non-destructive and non-invasive technique due to no changes in the material under test during the measurement [14].

\subsection{Part D: Structure of MRR}

The MRR was designed and simulated at $1.1 \mathrm{GHz}$ resonant frequency based on the PLA substrate. To produce the best performance of MRR in terms of sensitivity and Q-factor, the enhanced method of the coupling gap was applied. The coupling gap was $0.5 \mathrm{~mm}$ for both gaps that were located between the feed line and the ring, where the ring is not in a complete circle and the feed line was located in the middle of the gap. The enhancement of the coupling gap was implemented by inserting the feed line into a cut gap in the annular ring. The proposed design of the MRR, known as the key-shaped resonator, is shown in Figure 1, while Table 1 shows the parameters of the MRR.

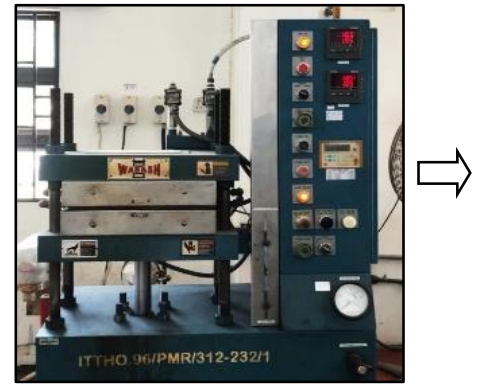

(a)

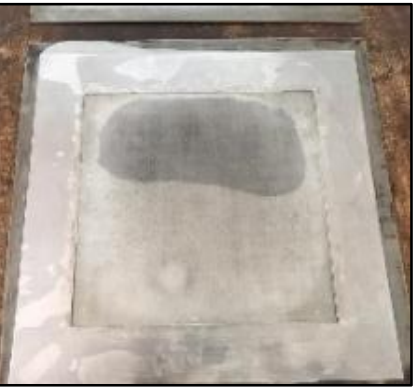

(b)

Figure 2. Fabrication process of PLA substrate, (a) Hot press machine, (b) PLA substrate

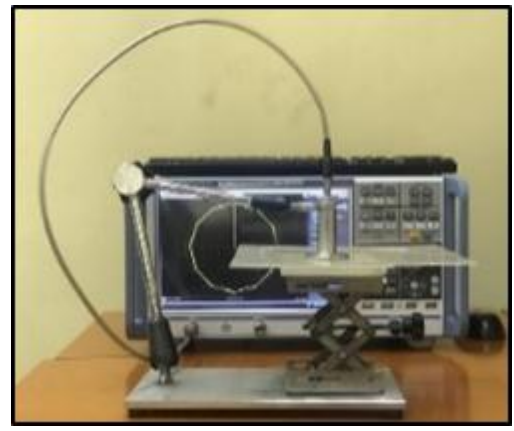

Figure 3. The open-ended coaxial probe for the determination of dielectric properties of PLA substrate 
Table 1. Dimension of MRR

\begin{tabular}{cccc}
\hline Parameters & Unit & Conventional MRR & Enhanced MRR \\
\hline Width of feed line, $w_{f}$ & $\mathrm{~mm}$ & 1.00 & 1.00 \\
Feed line length, $l_{f}$ & $\mathrm{~mm}$ & 37.40 & 37.05 \\
Coupling gap, $c_{g}\left(c_{g l}=c_{g 2}\right)$ & $\mathrm{mm}$ & 0.50 & 0.50 \\
Length of substrate, $l_{s}$ & $\mathrm{~mm}$ & 115.0 & 115.0 \\
Width of substrate, $w_{s}$ & $\mathrm{~mm}$ & 90.0 & 90.0 \\
Inner radius of ring, $R_{I}$ & $\mathrm{~mm}$ & 28.60 & 30.45 \\
Outer radius of ring, $R_{2}$ & $\mathrm{~mm}$ & 29.60 & 31.45 \\
\hline
\end{tabular}

\section{RESULTS AND DISCUSSION}

\subsection{Part A: Identification of PLA substrate properties}

After the fabrication process was completed, the measurements of the dielectric properties of the PLA were done. Figure 4 shows the result of the measurement properties of PLA in terms of dielectric constant and loss tangent. It is observed in Figure 4(a) that the variation of dielectric constant fluctuates starting from $1.05 \mathrm{GHz}$ to $1.2 \mathrm{GHz}$. At resonant frequency of $1.1 \mathrm{GHz}$, the intersected dielectric constant is at 2.25. Meanwhile, in Figure 4(b), the loss tangent varies from $1.05 \mathrm{GHz}$ to $1.2 \mathrm{GHz}$. Again, it is observed the loss tangent's value that intersects at $1.1 \mathrm{GHz}$ is 0.0001 . Thus, the result of the PLA substrate properties agrees with the previous works as described by [23, 24].

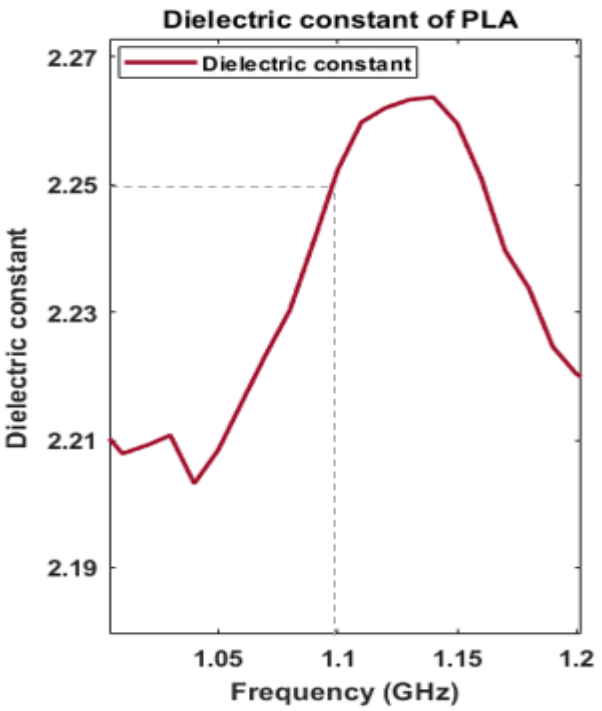

(a)

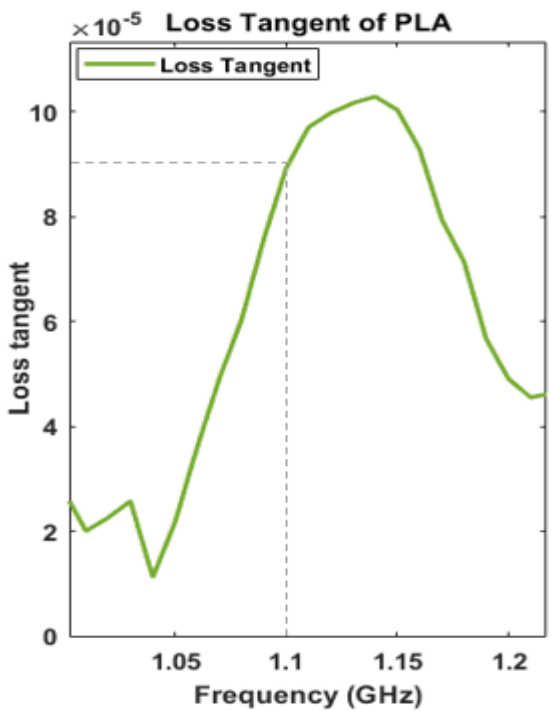

(b)

Figure 4. Measurement of the dielectric properties of PLA substrate, (a) Dielectric constant, (b) Loss tangent

\subsection{Part B: Simulation and measurement results of microwave ring resonator}

This part is mainly about the performances of the MRR for the conventional and enhanced MRR design. The main elements of the analysis are return loss, bandwidth and Q-factor. The return loss is observed based on the simulation and the measurement, where the reflection coefficient is below $-3 \mathrm{~dB}$. The MRR bandwidth refers to the range between the high and low frequencies when the return loss drops at $-3 \mathrm{~dB}$. Thus, the performance of the Q-factor will be determined. Due to the high performance of its Q-factor, the resonator can act as a sensor in microwave applications [25].

Figure 5(a) shows the return loss of the conventional MRR design based on the simulation and the measurement at the resonant frequency of $1.1 \mathrm{GHz}$. It is clearly shown that the simulation result is good compared with the measurement result, which are $-5.37 \mathrm{~dB}$ and $-5.02 \mathrm{~dB}$, respectively, with an absolute difference of $0.35 \mathrm{~dB}$. Meanwhile, the bandwidth of the measurement is narrow compared with the simulation, which are $0.012 \mathrm{GHz}$ and $0.018 \mathrm{GHz}$, respectively. Therefore, the Q-factor of the measurement is high with 183.33 compared with the Q-factor of the simulation, which is 122.22.

Essentially, the return loss of both methods fulfills the performance of the return loss, which is lower than $-3 \mathrm{~dB}$. But a narrow return loss, narrow bandwidth and high Q-factor will produce a good 
performance for the resonator to act as a sensor. Thus, the enhanced design was proposed to overcome the low performance of the resonator and produce a better performance with a high-sensitivity sensor.

Figure 5(b) presents the return loss of the enhanced MRR design based on the simulation and the measurement. It is found that the simulation result is narrow compared with the measurement result, which are $-26.67 \mathrm{~dB}$ and $-20.23 \mathrm{~dB}$, respectively, with an absolute difference of $6.44 \mathrm{~dB}$. The bandwidth and Q-factor of the simulation of the enhanced MRR design are $0.018 \mathrm{GHz}$ and 122.22, respectively, while the bandwidth and Q-factor of the measurement are $0.011 \mathrm{GHz}$ and 200, respectively. The measurement of the enhanced MRR design shows a narrow bandwidth and a high Q-factor with an absolute difference of $0.007 \mathrm{GHz}$ and 77.78, respectively, compared with the simulation. Based on the observation, the enhanced MRR design performs better performance compared with the conventional MRR design due to the performances of the return loss and Q-factor. Thus, the PLA substrate can be an option to replace the PCB substrate. Theoretically, as described in [26], the resonant frequency is inversely proportional to the dielectric constant. Hence, the increased dielectric constant will result in a lower resonant frequency. Moreover, the resonant frequency is directly proportional to the Q-factor, as described in (8).

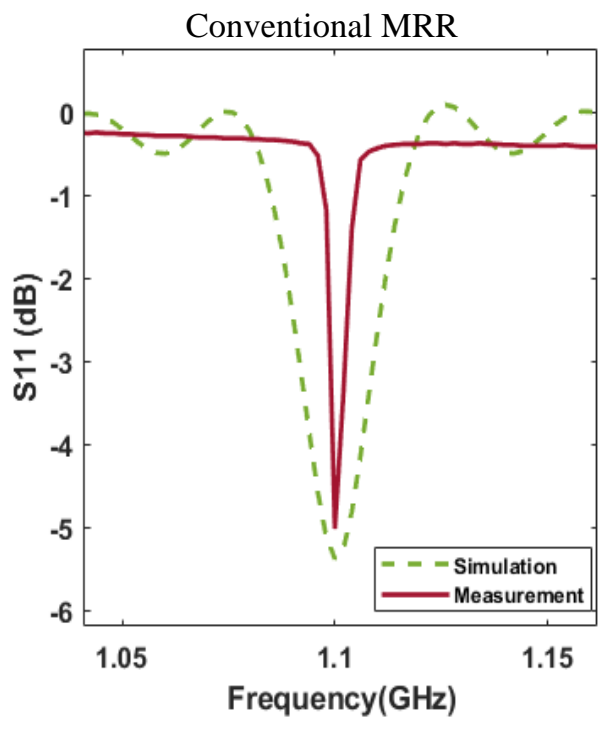

(a)

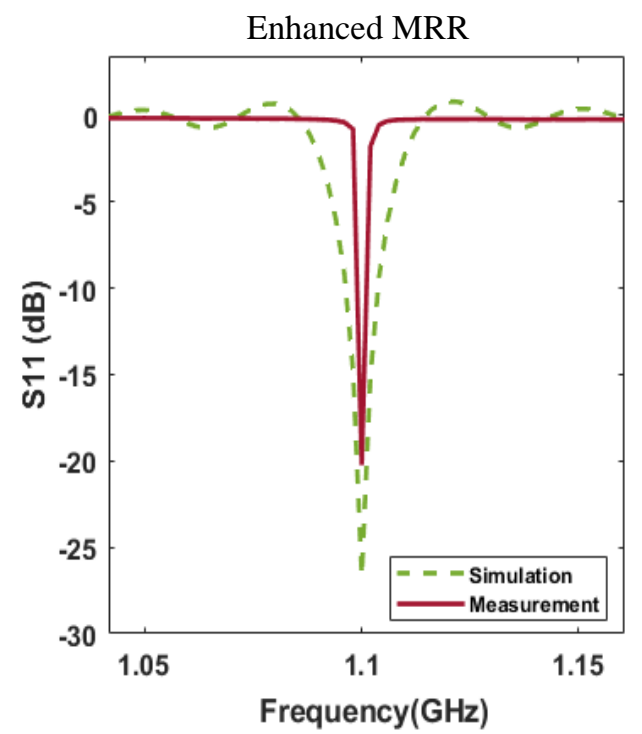

(b)

Figure 5. Return loss of, (a) Conventional design, (b) Enhanced MRR design

Table 2 shows the state art based on previous studies. It is found that the two-port MRRs were based on the PCB substrate and operated at $1 \mathrm{GHz}$, while the proposed MRR was designed with a single port and operated at $1.1 \mathrm{GHz}$ resonant frequency based on a thermoplastic substrate. The frequency operates at $1.1 \mathrm{GHz}$ due to the stability of the performance of the resonator. The proposed MRR produces a better performance in terms of a narrow return loss of $-20.23 \mathrm{~dB}$ and a high Q-factor of 200 compared with the previous works. Furthermore, the proposed MRR design is simple and small-sized, costs less and is a green technology due to PLA substrate being a recyclable material [9]. Thus, the proposed MRR can be applied in microwave applications due to the good performance of the Q-factor [6].

Table 2. State of art

\begin{tabular}{|c|c|c|c|c|}
\hline $\begin{array}{l}\text { Previous work } \\
\text { Properties }\end{array}$ & [8] & [21] & [27] & Proposed MRR \\
\hline MRR & Two-port & Two-port & One port & One port \\
\hline Frequency & $1 \mathrm{GHz}$ & $1 \mathrm{GHz}$ & $1 \mathrm{GHz}$ & $1.1 \mathrm{GHz}$ \\
\hline Q-factor & - & 83.92 & - & 115.80 \\
\hline $\mathrm{S} 11 / \mathrm{S} 21$ & $\mathrm{~S} 21,-8.22 \mathrm{~dB}$ & $\mathrm{~S} 21,-20 \mathrm{~dB}$ & $\mathrm{~S} 11,-15 \mathrm{~dB}$ & S11, -20.17 \\
\hline Substrate & FR4 & FR4 & Rogers 5880 & PLA \\
\hline $\begin{array}{l}\text { Area } \times \text { thickness } \\
\left(\mathrm{mm}^{2} \times \mathrm{mm}\right)\end{array}$ & $16295.5 \times 1.6$ & - & $12337.5 \times 0.787$ & $10350 \times 1.6$ \\
\hline
\end{tabular}




\section{CONCLUSION}

The conventional and enhanced MRRs were designed, simulated and measured successfully based on a thermoplastic substrate (PLA) at the resonant frequency of $1.1 \mathrm{GHz}$. Based on the observation, the enhanced MRR design's performance is better than the performance of the conventional MRR design. The enhanced MRR design is proposed to overcome the low performance of the conventional MRR design. Hence, the novelty of the proposed MRR design is that a substrate based on PLA can be applied in RF and microwave applications due to the high Q-factor of the MRR and that it is a green technology. Further investigations will be held to improve the performance of the MRR.

\section{ACKNOWLEDGEMENTS}

This research is to fulfill the requirement of Grant GPPS, No Vot. H414 and supported by Research Fund E15501, Research Management Centre, Universiti Tun Hussein Onn Malaysia. Our thanks to our colleagues at Polymer Laboratory, FKMP and EM Center at University Tun Hussein Onn Malaysia who provided insights and expertise that greatly assisted the research.

\section{REFERENCES}

[1] David M. Pozar, "Microwave Engineering," Third Edit. John Wilet \& Sons, 2005.

[2] Dinesh C Dube, "Microwave Devices and Applications," New Delhi: Aplha Science, 2011.

[3] S. M. K. Azam, M. I. Ibrahimy, S. M. A. Motakabber, A. K. M. Z. Hossain, and M. S. Islam, "A miniaturized hairpin resonator for the high selectivity of WLAN bandwidth," Bulletin of Electrical Engineering and Informatics, vol. 8, no. 3, pp. 916-922, 2019.

[4] Annapurna Das Sisir K. Das, "Microwave Engineering," Chenna, India, 2001.

[5] I. S. Amiri, A. Nabih, and Z. Rashed, "Simulative study of simple ring resonator-based brewster plate for power system operation stability," Indonesian Journal of Electrical Engineering and Computer Science, vol. 16, no. 2, pp. 1070-1076, November 2019.

[6] K. Chang, "Microwave ring circuits and antennas," Wiley Ser. Microw. Opt. Eng., no. February, pp. x, 282 \$bill. $\$ c 24 \mathrm{~cm} ., 1996$.

[7] G. E. Chatzarakis and T. Education, "Review of Different Ring Resonator Coupling Methods," Proceedings of the 9th WSEAS International Conference on Telecommunications and Informatics, January, pp. 227-231, 2010.

[8] A. Kulkarni and V. Deshmukh, "Dielectric Properties Measurement Using Ring Resonator," International Journal of Science and Research (IJSR), vol. 4, no. 4, pp. 2361-2364, April 2015.

[9] J. W. Slijkoord, "Is Recycling PLA Really Better Than Composting?," 2015. [Online]. Available: https://3dprintingindustry.com/news/is-recycling-pla-really-better-than-composting-49679/.

[10] N. H. Manab, E. Baharudin, F. C. Seman and A. Ismail, "2.45 GHz Patch Antenna Based on Thermoplastic Polymer Substrates," 2018 IEEE International RF and Microwave Conference (RFM), Penang, Malaysia, pp. 93-96, 2018

[11] United States Environmental Protection Agency, "Workshop Materials on WEEE Management in Taiwan," Handout 10, Printed Circuit Board Recycling Methods, no. October, 2012.

[12] S. Boonsawat, "Proper disposal treatment for printed circuit board waste: the developoment of pyrolysis based recycling technology," International Journal of Environmental Engineering, vol. 1 no. 2, July 2014.

[13] J. Sohaili, S. K. Muniyandi, and S. S. Mohamad, "A Review on Printed Circuit Boards Waste Recycling Technologies and Reuse of Recovered Nonmetallic Materials," International Journal of Scientific and Engineering Research, vol. 3, no. 2, pp. 1-7, 2012.

[14] B. O. Riera, "Permittivity measurements using coaxial probes," M.S. Thesis, Universitat Politecnica De Catalunya, May, 2016.

[15] V. K. V. L.F Chen, C.K.Ong, C.P Neo, V.V Varadan, "Microwave Electronics Measurement and Materials Charaterisation," WILEY, 2004.

[16] M. Taha Jilani, P. W. Wong, M. A. Zakariya and Y. C. Lee, "Dielectric characterization of meat using enhanced coupled ring-resonator," 2014 IEEE Asia-Pacific Conference on Applied Electromagnetics (APACE), Johor Bahru, pp. 191-194, 2014.

[17] R. A. Alahnomi, Z. Zakaria, E. Ruslan, and A. A. M. Bahar, "A Novel Symmetrical Split Ring Resonator Based on Microstrip for Microwave Sensors," Measurement Science Review, vol. 16, no. 1, pp. 21-27, February 2016.

[18] M. T. Jilani, W. P. Wen, M. A. Zakariya and L. Y. Cheong, "Microstrip ring resonator based sensing technique for meat quality," 2013 IEEE Symposium on Wireless Technology \& Applications (ISWTA), Kuching, pp. 220-224, 2013.

[19] A. Kulkarni, "Material Characterization Using Ring Resonator," International Journal of Innovative Research in Computer and Communication Engineering., vol. 3, no. 10, pp. 9711-9715, October 2015.

[20] S. K. M. Khanfar, M. K. Mohd Salleh and Z. Awang, "Single-mode ring resonator for bandpass filter application," 2010 IEEE Asia-Pacific Conference on Applied Electromagnetics (APACE), Port Dickson, pp. 1-4, 2010. 
[21] A. Alhegazi, Z. Zakaria, R. A. Alahnomi, E. Ruslan and S. R. Ab Rashid, "Design of double ring resonator (DRR) for material properties measurement," 2016 6th International Conference on Intelligent and Advanced Systems (ICIAS), Kuala Lumpur, pp. 1-6, 2016.

[22] A. Alhegazi, Z. Zakaria, N. A. Shairi, T. Sutikno, R. A. Alahnomi, and A. I. Abu-Khadrah, "Analysis and investigation of a novel microwave sensor with high Q-factor for oil sensing," Indonesian Journal of Electrical Engineering and Computer Science, vol. 12, no. 3, pp. 1407-1412, 2018.

[23] G. Boussatour, P. -. Cresson, B. Genestie, N. Joly and T. Lasri, "Dielectric Characterization of Polylactic Acid Substrate in the Frequency Band 0.5-67 GHz," in IEEE Microwave and Wireless Components Letters, vol. 28, no. 5, pp. 374-376, May 2018.

[24] J. Bjorgaard, M. Hoyack, E. Huber, M. Mirzaee, Y. Chang, and S. Noghanian, "Design and Fabrication of Antennas Using 3D Printing," Progress In Electromagnetics Research C, vol. 84, no. May, pp. 119-134, 2018.

[25] R. A. Alhnomi, Z. Zakaria, E. Ruslan, and A. A. M. Bahar, "Symmetrical split ring resonator metamaterials for microwave biosensor," ARPN Journal of Engineering and Applied Sciences, vol. 11, no. 6, pp. 3938-3942, March 2016.

[26] K. Tachikawa, K. Sakakibara, N. Kikuma, H. Hirayama, K. Kumaki and S. Hori, "Transmission properties of dual-band loop slot Frequency Selective Surfaces on plastic board," 201215 International Symposium on Antenna Technology and Applied Electromagnetics, Toulouse, pp. 1-4, 2012.

[27] M. T. Jilnai, W. P. Wen, L. Y. Cheong, and M. Z. U. Rehman, "A microwave ring-resonator sensor for noninvasive assessment of meat aging," Sensors (Switzerland), vol. 16, no. 1, pp. 1-13, 2016.

\section{BIOGRAPHIES OF AUTHORS}

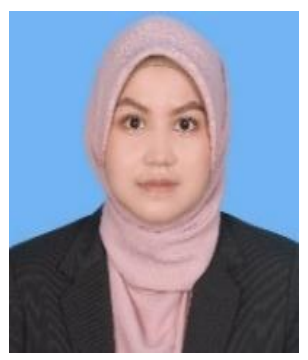

Nurul Hanani Manab was born in 1992. She received the Bachelor's in Electrical and Electronic Engineering from Universiti Tun Hussien Onn Malaysia (UTHM), Johor, in 2018. Her research area is engineering communication at Universiti Tun Hussien Onn Malaysia (UTHM), Johor.

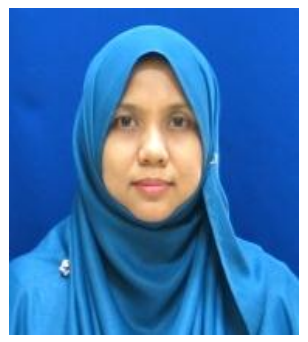

Elfarizanis Baharudin is a lecturer at the Faculty of Electrical and Electronic Engineering, Universiti Tun Hussien Onn Malaysia (UTHM), Johor in field Radio Frequency (RF) and Microwaves. She received her bachelor's degree in communication and computer engineering at Universiti Kebangsaan Malaysia (UKM), Malaysia in 2006. She also a member of the Institute of Electrical and Electronics Engineers (IEEE) at the international level, 2016. Her current research interests in material characterization, microwave and radio frequency.

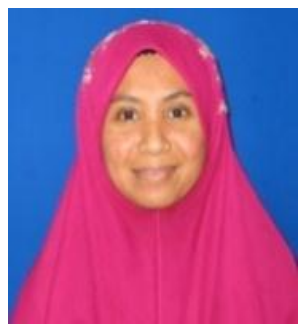

Fauziahanim Che Seman was born on. She received her Ph.D at Queen's University Belfast in Electrical Engineering, in 2011. She is a member of Institute of Electrical and Electronics Engineers (IEEE), chair of IEEE AP/MTT/EMC Society Malaysia Chapter and member of Board Engineers Malaysia (BEM) Lembaga Jurutera Malaysia. Her research interests in Radio Frequency (RF) and Microwaves, High-Frequency Selectivity (HFS).

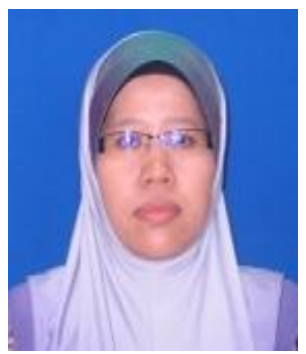

Rosnah Mohd Zin is a lecturer at the Faculty of Electrical and Electronic Engineering, Universiti Tun Hussien Onn Malaysia (UTHM), Johor. She received her bachelor's degree in Electrical and Electronic Engineering at Universiti Tun Hussien Onn Malaysia (UTHM), Johor, Malaysia in 2006. She also a member of the Institute of Electrical and Electronics Engineers (IEEE) at the international level, 2014. Her current research interests in Microelectronics. 